\title{
EXPERIMENTAL STUDY OF SOLITARY WAVE EVOLUTION OVER A 3D SHALLOW SHELF
}

\author{
Patrick Lynett ${ }^{1}$, David Swigler ${ }^{1}$, Sangyoung Son ${ }^{1}$, Duncan Bryant ${ }^{1}$, and Scott Socolofsky ${ }^{1}$
}

\begin{abstract}
A laboratory experiment was performed to investigate the three-dimensional turbulence and kinematic properties that develop due to a breaking solitary propagating over an irregular shallow water bathymetry. The bathymetry consisted of a deep water region connected to a shallow shelf via a relatively steep slope. The offshore boundary of the shelf break varied in the longshore direction, such that the shelf had a triangular shape in plan view, with the widest part of the shelf along the basin centerline. Free surface elevations and fluid velocities were measured using wave gauges and three-dimensional acoustic-Doppler velocimeters (ADVs), respectively. From the free surface elevations the evolution and runup of the wave was revealed; while from the ADVs, the velocity and turbulent energy was determined and specific turbulent events and coherent structures were indentified. It was found that significant shoaling was confined to areas with gentler sloping bathymetry near the basin side walls and the runup varied weakly in the alongshore direction. The runup was characterized by a refraction-generated jetting mechanism caused by the convergence of water mass near the basin centerline. The jetting mechanism caused the greatest cross-shore velocities to be located near the basin centerline. The greatest turbulent events were well correlated to borefronts, of which there were four, caused by the leading wave, beach reflections, and shelf-trapped oscillations. Along the shelf break, a large, shallow-water eddy developed which was found to have a peculiar three-dimensional flow field, where maximum velocity components were found at mid-depth.
\end{abstract}

Keywords: 3D turbulence; experiment; tsunami; breaking

\section{INTRODUCTION \& BACKGROUND}

The study and understanding of the kinematic properties and turbulent energy associated with a breaking wave is of particular importance when trying to predict wave forces on structures, nearshore mixing and circulations, sediment transport, and ultimately coastal morphology. There have been extensive experimental and numerical studies focused on furthering the knowledge of turbulence that develops as waves interact with an underlying bathymetry and break; these have largely focused on mean flows that are two-dimensional. The goal of this laboratory study was to understand the threedimensional turbulence and kinematic properties that developed as a solitary wave broke, evolved, and propagated over an irregular bathymetry.

To understand the physics that govern the evolution of waves as they approach a shoreline, numerous experimental studies have been conducted. The experiments have provided insight to specific phenomena that are known to occur such as shoaling, refraction, breaking, and turbulence. For example, Lin and Hwung (1992) performed a laboratory experiment and documented that the impinging jet impacts the water surface in front of the wave causing water to be splashed up vertically. Between the front face of the wave and the impinging jet, a tube of air becomes trapped significantly increasing the amount of air entrained in the water.

The entrained air along with the violent impact of the jet cause significant turbulence to develop within the water column as the flow transitions from irrotational to rotational motion (Ting and Kirby, 1995). The turbulence, or deviations from the mean flow, under a plunging breaker is much greater as compared to a spilling breaker (Ting and Kirby, 1994) and greatly depends on both the deep-water wave conditions and beach slope (Ting and Kirby, 1995). The turbulent energy is dissipated within one wave cycle and transported landward by the mean flow under a plunging breaker, while under a spilling breaker the turbulent energy is dissipated at a much slower rate and transported seaward (Ting and Kirby, 1994; Ting and Kirby, 1995).

The laboratory studies described above provide the building blocks to understanding the physics governing waves as they approach a shoreline. In this study, the characteristics of a breaking solitary wave over an irregular, three-dimensional bathymetry are presented. The basin and instrument layouts used in the experiment along with the procedures are described in Section 2. The validity of the free surface, velocity, and turbulence measurements is presented in Section 3. The evolution of a single solitary wave over a complex shallow water shelf, its runup on a planar beach, the resulting hydrodynamic are discussed in Section 4 with the use of visual observations, wave gauge measurements, and velocity measurements.

\footnotetext{
${ }^{1}$ Department of Civil Engineering, Texas A\&M University, College Station, TX, USA
} 


\section{EXPERIMENT SETUP \& PROCEDURE}

To better understand the turbulence and kinematic properties associated with a breaking solitary wave, a laboratory experiment was conducted, and free surface elevations and fluid velocities were recorded. The experiment was conducted in a large wave basin which was $48.8 \mathrm{~m}$ long and $26.5 \mathrm{~m}$ wide. It was equipped with a piston-type wavemaker which produced a single solitary wave. The depth at the wavemaker was $78 \mathrm{~cm}$ and the generated solitary wave had a height of $39 \mathrm{~cm}$. The walls and underlying bathymetry of the basin were made of smooth concrete. The coordinate system adopted for the study is the following: $\mathrm{X}=0$ at the wavemaker and increasing across the length of the basin; $\mathrm{Z}=0$ at the basin floor in the constant depth portion of the basin near the wavemaker with positive upward; and $\mathrm{Y}=0$ at the centerline of the basin with positive parallel to the wavemaker to agree with the right-hand rule.

A complex shallow water bathymetry constructed of concrete was built, shown in Figure 1, to force the generated wave to break symmetrically about the centerline of the basin $(\mathrm{Y}=0 \mathrm{~m})$. Starting at $\mathrm{X}=10.2 \mathrm{~m}$ and extending to $\mathrm{X}=25.5$, a three dimensional shelf was built. In plan view, the shelf was triangular in shape with the apex of the triangle closest to the wavemaker and the shoreward side flush with a 1:30 slope planar beach. The offshore shelf edge had an elevation of $Z=0.71 \mathrm{~m}$ with the apex located at $\mathrm{X}=12.6 \mathrm{~m}$. The shelf break varied in slope with the steepest slope at the apex, becoming milder moving along the shelf edge toward the basin side walls. The planar beach continued to $\mathrm{X}=31 \mathrm{~m}$ before becoming level and extending to the back wall of the basin. The still water shoreline (SWS) intersected the planar beach at $X=25.75 \mathrm{~m}$ and the water level was maintained at a depth of $0.78 \mathrm{~m}$ $(\mathrm{Z}=0.78 \mathrm{~m})$.

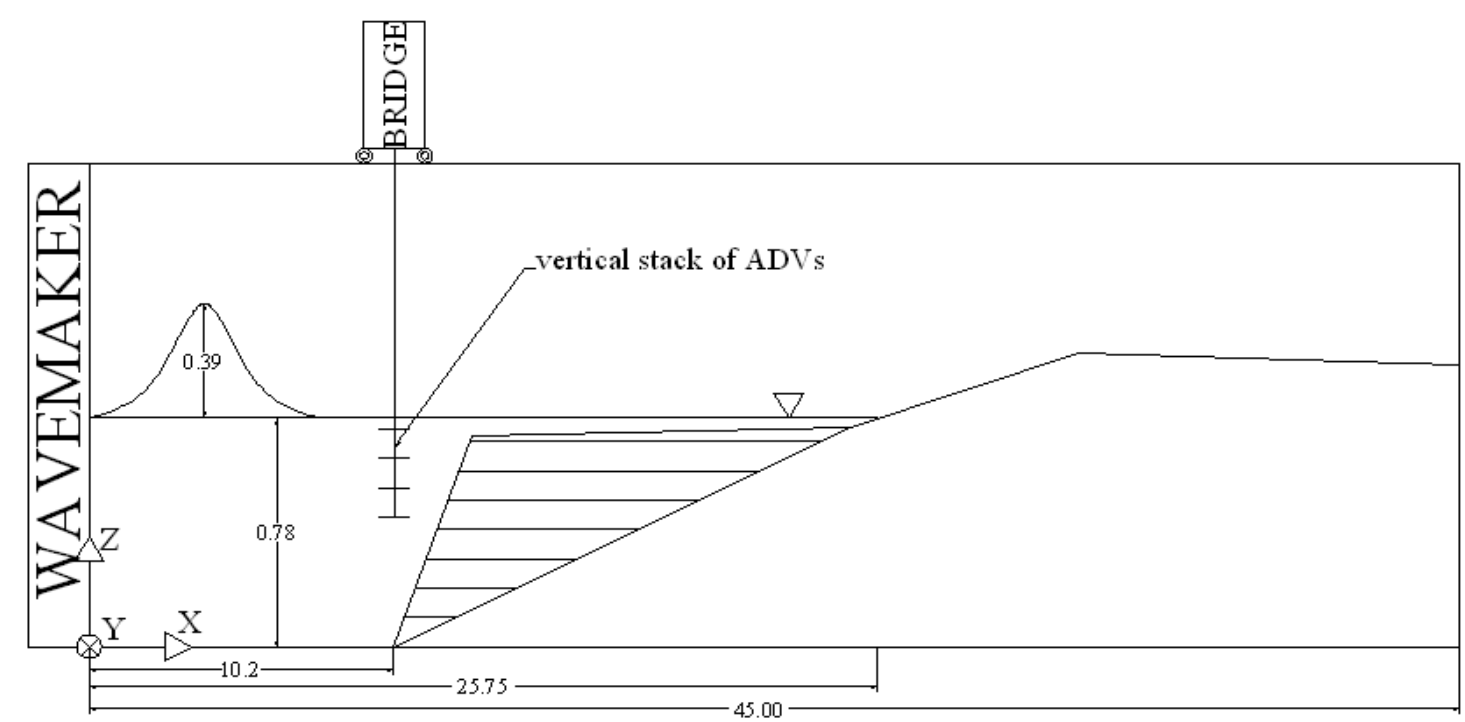

Figure 1. Elevation view of experiment setup. All dimensions are in meters.

During the experiment, a variety of instruments were used to record the free surface elevation and fluid velocities associated with a breaking solitary wave. Two types of wave gauges were used to measure the free surface, and acoustic-Doppler velocimeters (ADVs) were used to measure fluid velocities. The data measured by the instruments was recorded by a data acquisition system (DAQ) which allowed measurements to be made at a sampling frequency of $50 \mathrm{~Hz}$. Instruments were mounted to the basin bottom with brackets and to the bridge which was positioned at various cross-shore locations to allow the basin to be methodically covered. Due to the variety and limited number of instruments available, each type of instrument was deployed separately and moved to various locations within the basin, providing a detailed representation of the dynamics experienced during the experiment while reducing the impacts to the flow due to instrumentation interference.

The wave gauges were used to measure the free surface elevation, allowing the evolution of the solitary wave over the shallow water shelf and up the planar beach to be documented. To do this, two types of wave gauges were required due to the widely varying depth of water offshore and onshore of the SWS during the experiment. The two types included resistance-type, wire wave gauges (WG), used offshore of the SWS, and ultra sonic wave gauges (usWG), used onshore of the SWS.

For the study, a total of 14 WGs were used and attached to the bridge. The WGs were positioned on the bridge in the longshore direction with one meter spacing from $\mathrm{Y}=-12 \mathrm{~m}$ to $\mathrm{Y}=12 \mathrm{~m}$. The bridge 
was then positioned at multiple cross-shore locations including $X=5,7.5,9,11.5,13,15,17,19,21,23$, and $25 \mathrm{~m}$. In total, there were 275 different WG locations throughout the basin as shown by (*) in Figure 2.

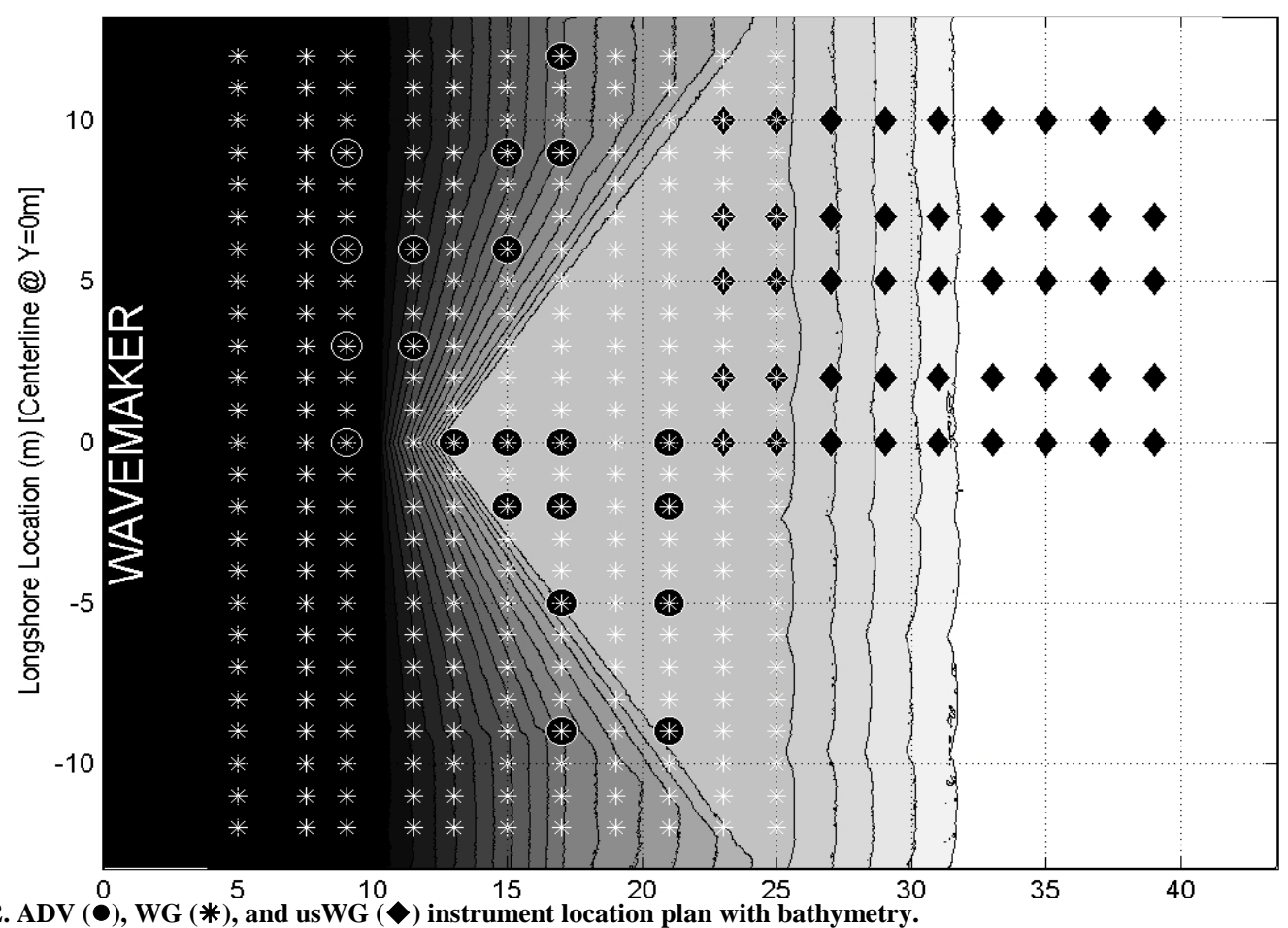

Figure 2. ADV $(\bullet)$, WG $(*)$, and usWG $(\diamond)$ instrument location plan with bathymetry.

Once the breaking solitary wave reached the SWS, the usWGs were used to track its propagation up and down the planar beach. For the experiment, five usWGs were located on the bridge at $\mathrm{Y}=0,2$, 5,7 , and $10 \mathrm{~m}$ which were then positioned at $\mathrm{X}=23,25,27,29,31,33,35,37$, and 39m. The first two bridge locations of the usWG layout were the same as the last two bridge locations of the WG layouts to co-locate the two types of instruments and compare the consistency of the free surface time series recorded. In total, there were 45 usWG locations throughout the basin as shown by $(\bullet)$ in Figure 2.

To measure the fluid velocities, eleven Nortek Vectrino 3D ADVs were employed which recorded all three components of velocity $(U, V$ and $W$ ) simultaneously. Eight of the ADVs were mounted to the bridge in two vertical stacks of four to obtain a vertical profile as shown hanging from the bridge in Figure 1 . On the stacks, the ADVs were spaced $10 \mathrm{~cm}$ apart in the vertical and were positioned in the water so that the uppermost submerged ADV was $5 \mathrm{~cm}$ below the still water surface. As the vertical stacks were positioned closer to the shelf, the water depth due to the bathymetry became shallower and did not allow all of the ADVs on the stack to be completely submerged. At those locations, the stacks were positioned as close to the bathymetry surface as possible without touching. The remaining ADVs were mounted to the bathymetry on or near the shelf. Due to the limited number of instruments, the ADVs were deployed in multiple configurations amounting to a total of 51 locations throughout the basin. The ADVs are shown by $(\bullet)$ in Figure 2 with the bottom mounted instruments being the 11 locations with coordinates of $\mathrm{X} \geq 13 \mathrm{~m}$ and $\mathrm{Y} \leq 0 \mathrm{~m}$. The remaining 10 locations shown in Figure 2 are the bridge mounted vertical stacks of ADVs consisting of four instruments each.

For each trial of the experiment, a single solitary wave, $0.39 \mathrm{~m}$ in height, was generated and then propagated over the shallow water shelf, creating a strongly plunging breaker. The combination of the symmetric bathymetry and the drastic reduction in water depth on the shelf caused the wave to begin breaking violently just onshore of the shelf apex and extend laterally to the basin side wall as the wave moved further onshore.

The wave heights and fluid velocities were measured separately, with the same initial conditions, in order to not affect the data collected due to the basin's dense population of instruments. For each type of measurement device, multiple trials were conducted to ensure the consistency of the data. A trial consisted of generating a single wave with the wavemaker and recording data using the DAQ for 
approximately two minutes. After each trail, the basin was allowed to calm for 35 minutes before another trial was initiated, which was found to be a sufficient duration for any circulations to diminish.

For both the WGs and usWGs, two trials were run at each location to confirm the consistency of the time series, as well as the repeatability of the waves generated by the wavemaker. For the ADVs, a minimum of 20 trials for each location were performed, which permits a reasonable quantification of the mean and the turbulent fluctuations. It is noted that the dataset presented here was generated from over 500 individual trials, all using the identical depth and wave condition.

In order to obtain turbulent quantities, multiple trials had to be run for each ADV location recording the instantaneous velocity $(U, V$ and $W$ ) time series. After recording at least 20 trials and removing bad data associated with aeration and instrument emergence, the instantaneous velocity time series were ensemble averaged to establish the time history of mean flow $(\bar{U}, \bar{V}$ and $\bar{W})$ at the instrument location Once the mean flow was determined, the time history of instantaneous turbulent fluctuations $\left(u^{\prime}, v^{\prime}\right.$ and $\left.w^{\prime}\right)$ for each trial were calculated by subtracting the mean flow from the instantaneous time series. At this point, the Reynolds stresses could be quantified using similar techniques as previously done by Ting (2005), for example. The average Reynolds stresses $\left(\overline{u^{\prime} u^{\prime}}, \overline{v^{\prime} v^{\prime}}, \overline{w^{\prime} w^{\prime}}, \overline{u^{\prime} v^{\prime}}, \overline{u^{\prime} w^{\prime}}\right.$ and $\overline{v^{\prime} w^{\prime}}$ ) were calculated by multiplying the various combinations of the instantaneous turbulent fluctuation components together for each trail and then ensemble averaged to obtain a time series of the Reynolds stresses. Using the Reynolds stresses, the total turbulent kinetic energy ( $K$ ) was quantified:

$$
K(t)=\frac{\overline{u^{\prime} u^{\prime}}+\overline{v^{\prime} v^{\prime}}+\overline{w^{\prime} w^{\prime}}}{2}
$$

The total turbulent energy is of particular usefulness as it provides a single time series which includes all three primary components of the stresses.

The single solitary wave generated for each trial of the experiment created a very repeatable, yet complex flow throughout the basin. In particular, multiple borefronts and reflected waves developed on the shelf due to the flows' interaction with the bathymetry. To discuss the complexity of the free surface, fluid velocity, and turbulent energy, a complete conceptual understanding of the hydrodynamics is needed, and this can be extracted from imagery recorded during the trials.

To depict the features that developed and evolved in the basin, multiple planview images of the southern half the basin $(\mathrm{Y} \leq 0 \mathrm{~m})$ are provided in Figure 3. The images provide a visual explanation of the experiment, which will be vital to understanding the data presented throughout this paper. The wave generated by the wavemaker propagated from left to right in the images (in the cross-shore direction) as it encountered the shelf, broke, and traveled up the planar beach. The centerline of the basin $(Y=0 \mathrm{~m})$ passes through the apex of the shelf near the top of the images. The side wall of the basin is along the bottom of the images and the wavemaker to the left; both of which are outside the field-of-view. The vertical black line on the left side of the images indicates the end of the constant depth portion of the tank and the offshore limit of the shelf break, while the vertical black line on the right gives the start of the planar beach. The V-shaped diagonal black lines delineate the edge of the flat portion of the shallow water shelf, or the shelf edge. Green areas that can be seen near the bottom of some of the images are from a dye visualization study; dye was released from a continuous point source at the shelf edge.

The images are organized by time, where time $=0$ corresponds to the initial activation of the wavemaker, a fraction of a second before the paddles start to move. Figure 3a shows the solitary wave arriving at the apex of the shelf edge and beginning to break; the time here is 6.2 seconds. Breaking began just onshore of the shelf apex along the centerline. The initial impact of the overturning jet with the water surface, characteristic of a plunging breaker, can be seen as a dense localized white area. This was the initiation of the borefront associated with the generated wave and is labeled as borefront\#1. The white arrows denote the flow associated with borefront\#1 was, as expected, onshore.

At 8.3 seconds, Figure $3 \mathrm{~b}$ shows that the breaking of borefront\#1 extending to the basin side wall. The flow behind borefront\#1 is still onshore in the direction of wave propagation (white arrows), while on top of the shelf just landward of the apex, the flow is weakly offshore (black arrows) due to the small trough behind the solitary wave. At the apex, the water is directed onshore as a shelf-generated secondary, labeled as borefront\#2, evolves. The physical situation leading to borefront\#2 is akin to relaxing flow over a sill, where the hydraulic jump in the lee of the sill will propagate as a free wave over and away from the sill when the current decreases adequately. For reference throughout the paper, 
this type of generation mechanism will be called "sill-type". It is worthwhile to note that the apex of the shelf became dry for a short period preceding the arrival of borefront\#2. At this point in time, the green dye injection starts near the bottom of the image. The dye is not yet visible at this time, but can be seen clearly in the next frame advecting landward due to the onshore flow following borefront (1).

At 16.1 seconds, Figure 3c shows the shoreward propagation of borefront\#2 over the shallow water shelf and the associated onshore flow. Borefront\#3, visible further onshore, is a portion of borefront\#1 reflected off the top of the planar beach, generating an offshore flow. Figure 3d shows the same two borefronts as Figure 3c, but 4 seconds later, after passing through each other. The green dye can be seen mixing along the shelf edge near the basin side wall due to the offshore flow following borefront\#3.

Approximately 6 seconds later, shown in Figure 3e, borefront\#2 has traveled to the right beyond the field-of-view, while borefront\#3 converges at the apex of the shelf. This convergence is a refraction phenomenon, where the offshore-directed wave energy is turning towards the apex, and essentially propagates along the shelf edge. The flow on the shelf is still strongly directed offshore, as can be seen by the green dye transported offshore of the shelf edge. Near the apex, borefront\#3 converges strongly enough to break; an occurrence caught clearly in the data as a significant turbulent event, to be discussed later. Along the shelf edge, the offshore flow leads to the formation of a nearly stationary hydraulic jump.

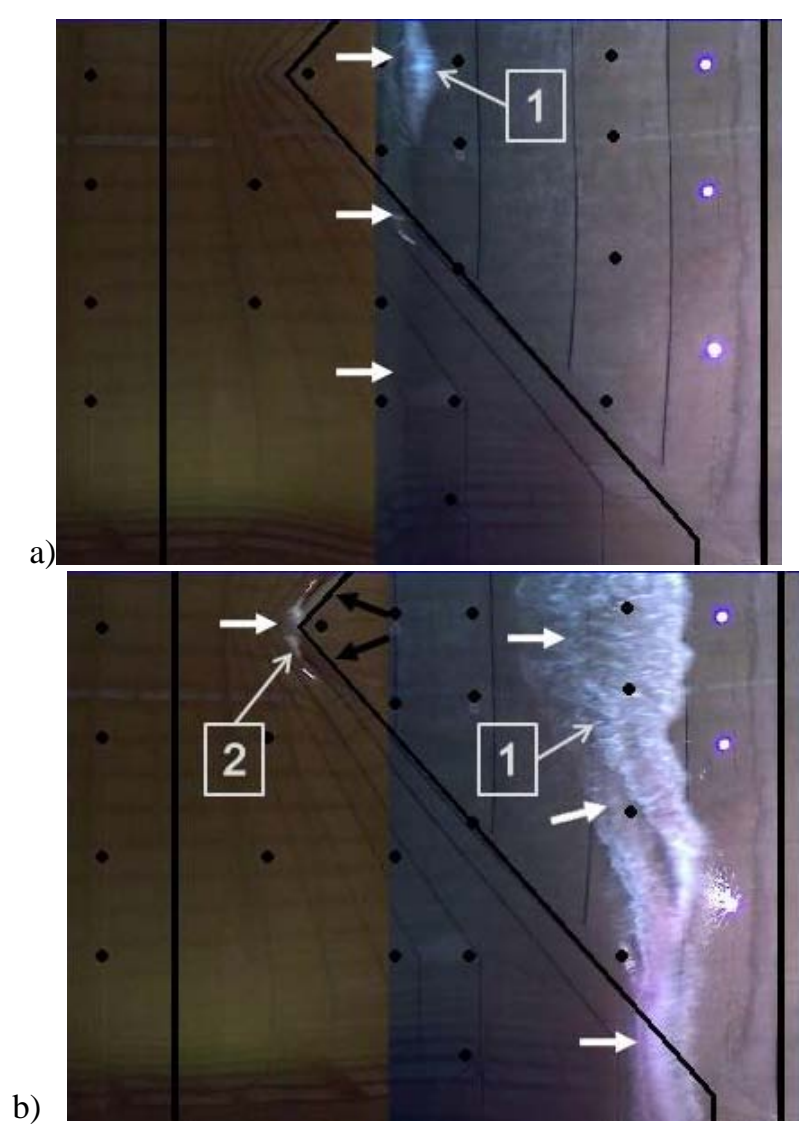



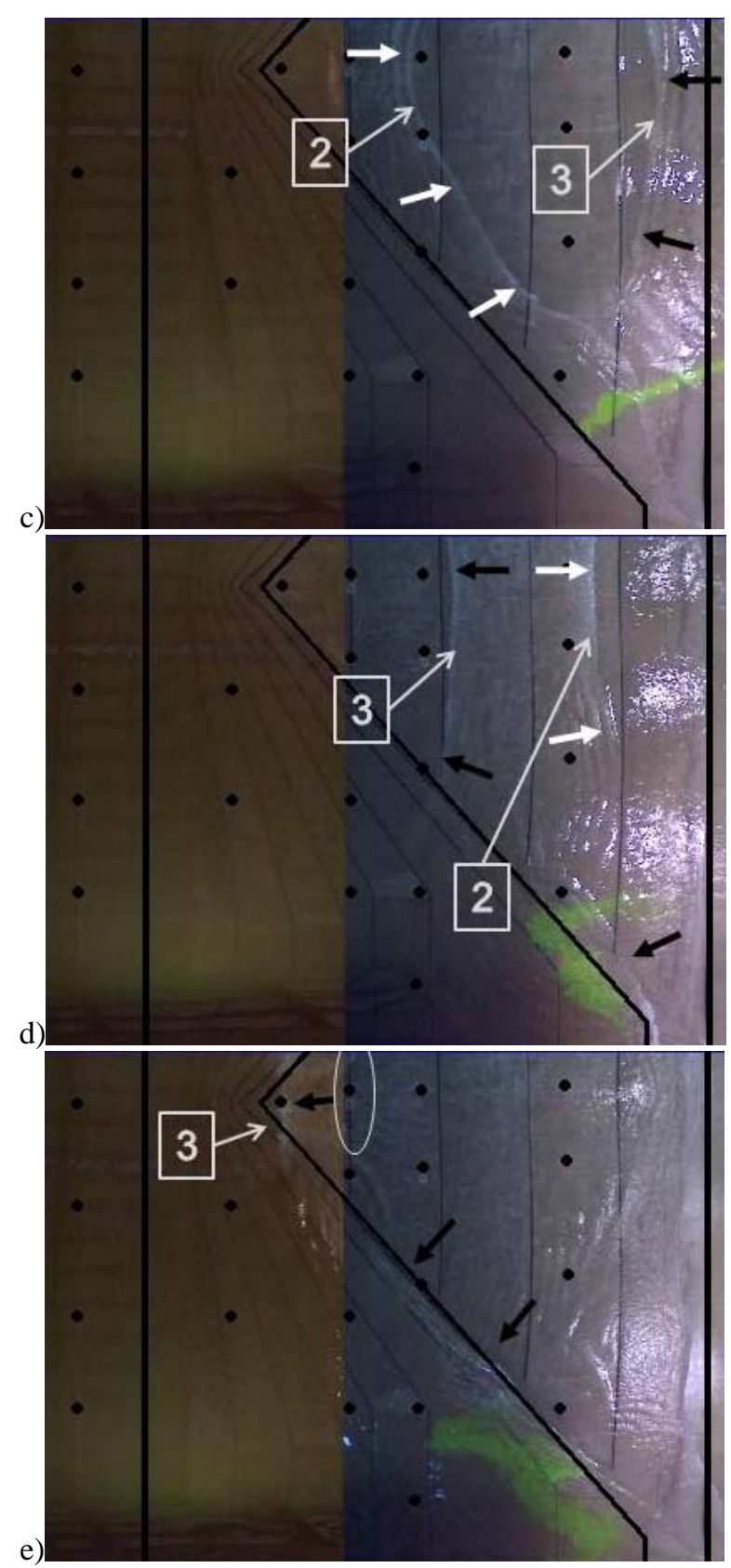

Figure 3. Images of the basin at a) $6.2 \mathrm{~s}$, b) $8.3 \mathrm{~s}$, c) $16.1 \mathrm{~s}$, d) $22.1 \mathrm{~s}$, and e) $26.4 \mathrm{~s}$ after the solitary wave was generated. ADV locations, $(\rightarrow)$ mean flow direction with white arrows indicating onshore flows and black arrows indicating offshore flows. Note that an animation of the images shown above can be viewed in Movie 2 of the Supplementary Material.

With the presentation of the hydrodynamic features in the previous section, data collected by WGs can be analyzed with a greater degree of understanding. Maximum free surface elevations are, naturally, associated with the leading solitary wave (borefront\#1 on the shelf) and are shown in Figure 4. The straight black line near $\mathrm{X}=10.2 \mathrm{~m}$ marks the landward end of the constant depth portion of the basin while the diagonal, black line represents the edge of the triangular, shallow water shelf, similar to Figure 3. Wave height is highly uniform offshore of the shelf. As discussed in Figure 3, breaking begins at the apex, spreading laterally along the shelf edge. The breaking is evident in Figure 4 by the rapid decay in wave height at the shelf edge. A particular area of interest is the region just offshore of the shelf edge near the basin side wall. In this region, the wave increases to its maximum height due to shoaling. In this area are found the mildest offshore bottom slopes, providing the reasonable conclusion 
that shoaling is a weak effect on short (relative to the wavelength), although very steep, slopes as compared to longer, mild slopes.

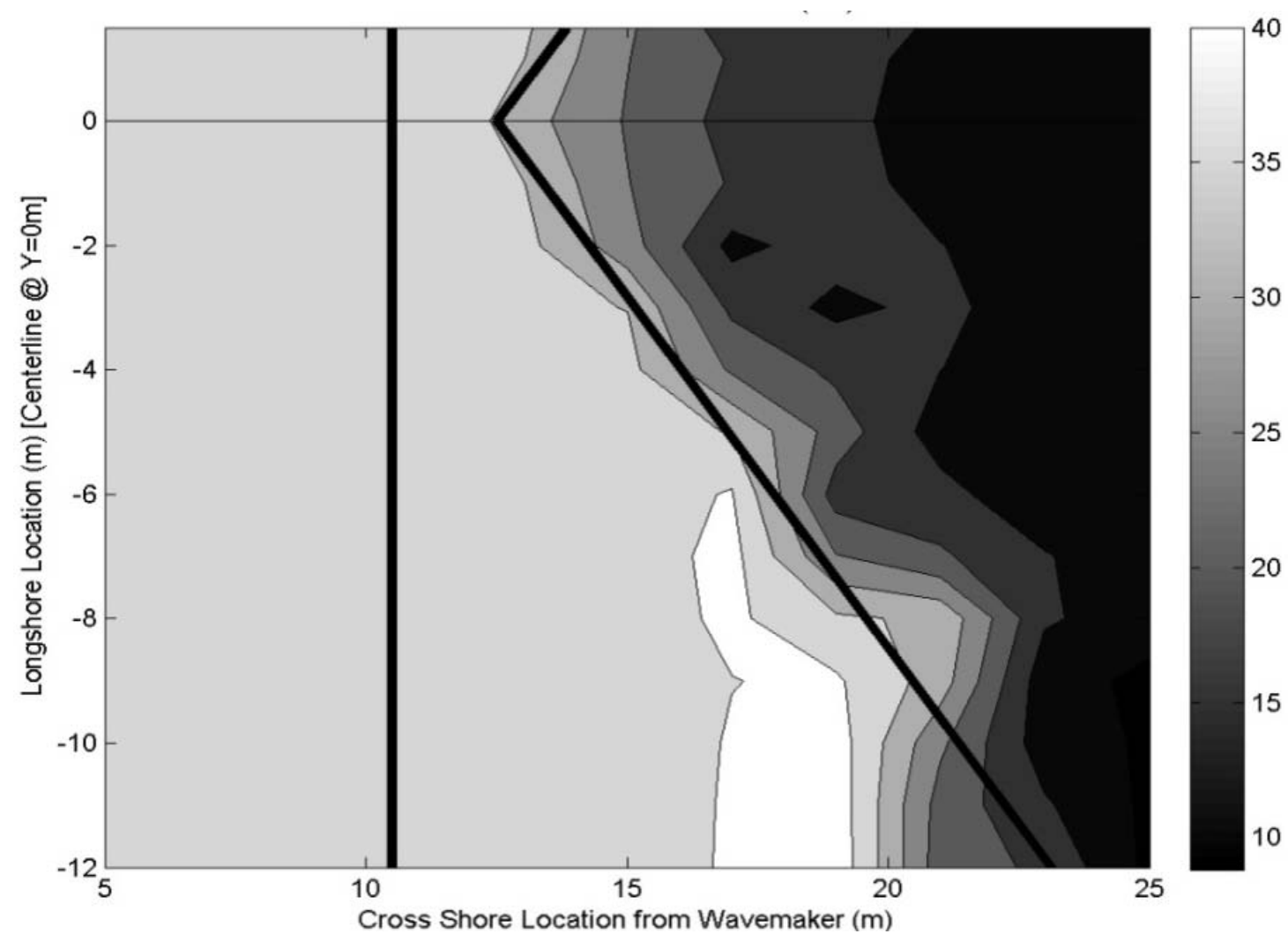

Figure 4. WG maximum free surface elevation $(\mathrm{cm})$. Black lines, from left to right, denote the end of constant depth portion of the tank and the shelf edge.

By understanding the evolution of the generated solitary wave and its decay in wave height as it propagated over the shelf, the additional borefronts, as described in Figure 3, can be more readily analyzed. Here, the free surface elevations recorded by multiple WGs along the centerline of the basin beginning offshore of the apex and moving onshore are first provided. The cross-shore locations of WGs along $Y=0 \mathrm{~m}$ included $\mathrm{X}=7.5 \mathrm{~m}, 11.5 \mathrm{~m}, 13.0 \mathrm{~m}, 15.0 \mathrm{~m}, 17.0 \mathrm{~m}$, and $21.0 \mathrm{~m}$ which allowed the time and spatial lag of the individual borefronts in relation to each location to be revealed. The four borefronts that were identified in Figure 3 are labeled similarly and depicted in Figure 5 by four gray lines with (1) representing the generated solitary wave, (2) representing the sill-type secondary borefront, (3) representing the reflected borefront, and (4) representing the last, also sill-type, borefront. The direction of propagation of the borefronts can easily be determined by looking at the slope of the gray lines; a negative slope denotes borefronts that were traveling onshore while a positive slope denotes the borefront that was traveling offshore.

Starting with the gray line labeled (1), the two offshore locations at $\mathrm{X}=7.5 \mathrm{~m}$ and $11.5 \mathrm{~m}$ show the solitary wave as it traveled in the constant depth portion of the tank. Moving onshore, at 13.0m, the front face of borefront (1) is approaching vertical just prior to breaking. By the time borefront (1) reached $\mathrm{X}=15.0 \mathrm{~m}$, breaking had begun as revealed by the decay in wave height, although the jet, associated with a plunging breaker, impacted the water slightly shoreward of this location as shown in Figure 3a. At $X=17.0 \mathrm{~m}$ and $21.0 \mathrm{~m}$, the height of borefront (1) had decreased significantly as it traveled further onshore. Borefront (2) followed on the shelf after the trough created by borefront (1) and could be tracked in the data as it traveled onshore and passed through borefront (3) at a point between $\mathrm{X}=17.0 \mathrm{~m}$ and $\mathrm{X}=21.0 \mathrm{~m}$, as shown by the crossing of the gray lines. The height of borefront (3) grew suddenly at $\mathrm{X}=13.0 \mathrm{~m}$ as it traveled offshore and converged due to refractive focusing, which was described in relation to Figure 3e. The event $(\rightarrow)$ at $X=15.0 \mathrm{~m}$ is a result of this convergence, and led to local breaking. Borefront (4) was visually only seen on the shelf after the offshore flow associated with borefront (3) subsided. 

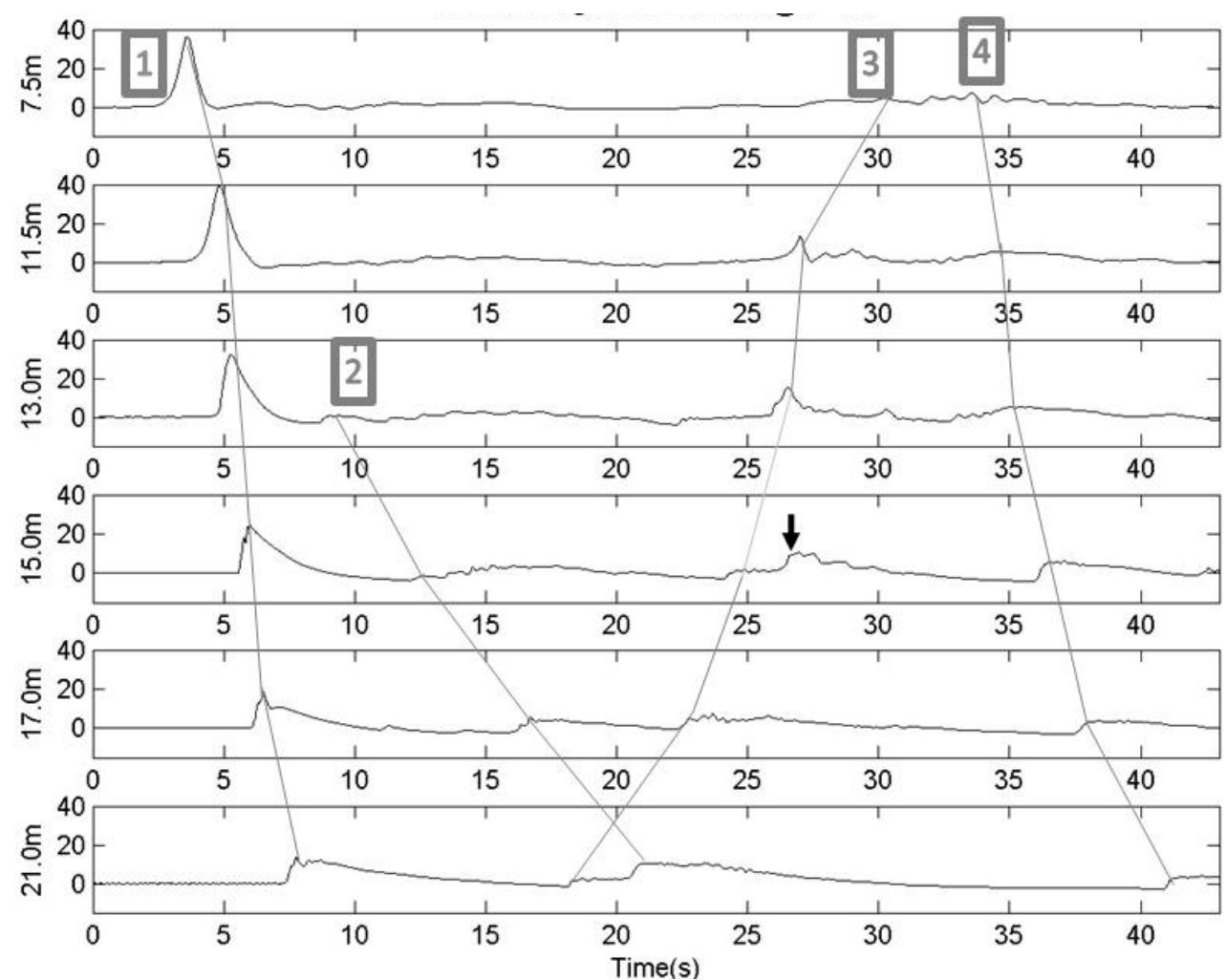

Figure 5. WG free surface elevation $(\mathrm{cm})$ over time of several WGs located along the centerline of the basin (Y=0m). Gray lines show identified borefronts, (1) generated wave, (2) secondary borefront, (3) reflected borefront, and (4) return wave/borefront, and times they pass each WG. $(\rightarrow)$ Denotes localized event.

The visually observed hydrodynamic and free surface displacements provide a picture of the features that develop during the experiment with respect to the free surface, but in order to understand the dynamics below the water surface, the fluid velocity was investigated. To do this, all three components of the mean fluid velocity measured by the ADVs throughout the basin are used to extract and quantify turbulence.

To reveal the interdependence between the mean flow and the turbulence, Figure 6 shows the three components of the mean flow, their RMS turbulent fluctuations, and $\mathrm{K}$ at the apex of the shelf. This location provides complete ADV data, as the incident solitary wave had not yet begun to break at this location, and the flow depth remained deep enough so as to keep the ADV submerged at all times. Looking first to the mean flow (top three subplots), clearly and expectedly $\bar{U}$ is dominant, with a peak speed of nearly $2 \mathrm{~m} / \mathrm{s}$ under the crest of the wave. The $\bar{V}$ is, also expectedly, small due to the centerline measurement location of a symmetric problem. Interestingly, the vertical component of the mean flow, $\bar{W}$, shows only a very small positive (upward) velocity associated associate with the rising crest of the incident solitary wave. This is not consistent with potential flow theory, and indicates the possibility that shear and rotationality driven by the nonlinear wave traveling up the steep slope are important to the kinematics in this region. The RMS fluctuations indicate numerous different events, or peaks in magnitude, which often correlate to changes in the flow direction of at least one of the mean components. These peaks are similar in value across all three components. This figure also provides some guidance as to the relative magnitude of the turbulence created by the borefronts and that generated by bottom friction due to the smooth concrete bathymetry. Near 15 seconds, the flow in at the apex is characterized as slowly varying onshore flow, without any neighboring flow transitions in temporal space; the magnitude of the turbulent energy at this time is low. Compare with the flow properties at a time of 35 seconds, which shares similar magnitudes in the mean flow, but is immediately after the passage of borefront 4. The square root of the turbulent kinetic energy, $\sqrt{K}$, associated with the passage of borefronts is 6-10 times larger than that driven by bottom stress during quasi-steady flow. 

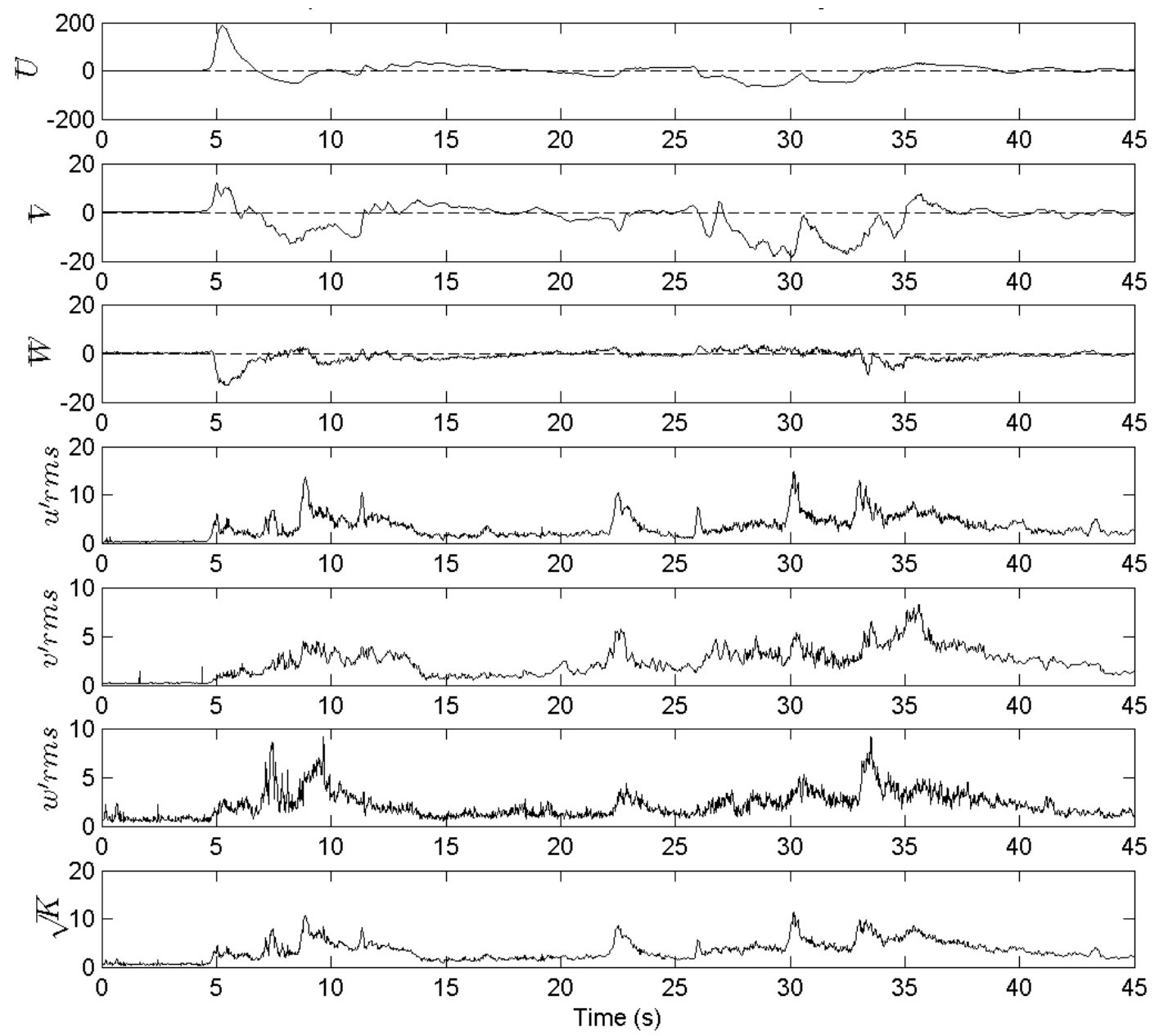

Figure 6. Mean velocities (top three subplots), RMS turbulent fluctuations (next three plots), and square root of turbulent kinetic energy (bottom plot) at the apex of the shelf; all units in $\mathrm{cm} / \mathrm{s}$.

With the hydrodynamics of the basin and the evolution of the generated solitary wave over the shallow water shelf described, the next area of interest is shoreward of the SWS. Specifically, the area included the planar beach extending beyond the SWS at $\mathrm{X}=25.75 \mathrm{~m}$ where the usWG were used to track the wave's runup. By tracking the runup, the velocity in the cross-shore direction (U component) was then determined.

The runup of the solitary wave was tracked through determining the time that borefront (1) reached each location. These borefront (1) arrival times are given in the left plot of Figure 7. Naturally, the earliest arrival times occur at the lowest part of the initially dry beach near $X=27 \mathrm{~m}$ after about 9 seconds, while the latest arrival times occur at $\mathrm{X}=39 \mathrm{~m}$, at the top of the planar beach, after about 16 seconds. The variations of the contour lines revealed that the shape of the wave front was not alongshore-uniform as it moved up the beach. For example, at $X=29 \mathrm{~m}$ the borefront arrived first near the basin side wall and a bit later at the centerline. The later arrival time near the basin centerline at $\mathrm{X}=29 \mathrm{~m}$ was due to refraction effects and the fact that along the centerline where the shelf is widest, the wave travels over a longer distance of very shallow water. It was interesting to find that as the runup continued shoreward, its original alongshore orientation had essentially inverted by the time it reached $\mathrm{X}=39 \mathrm{~m}$. The borefront arrived first near the centerline and last near the basin wall. 

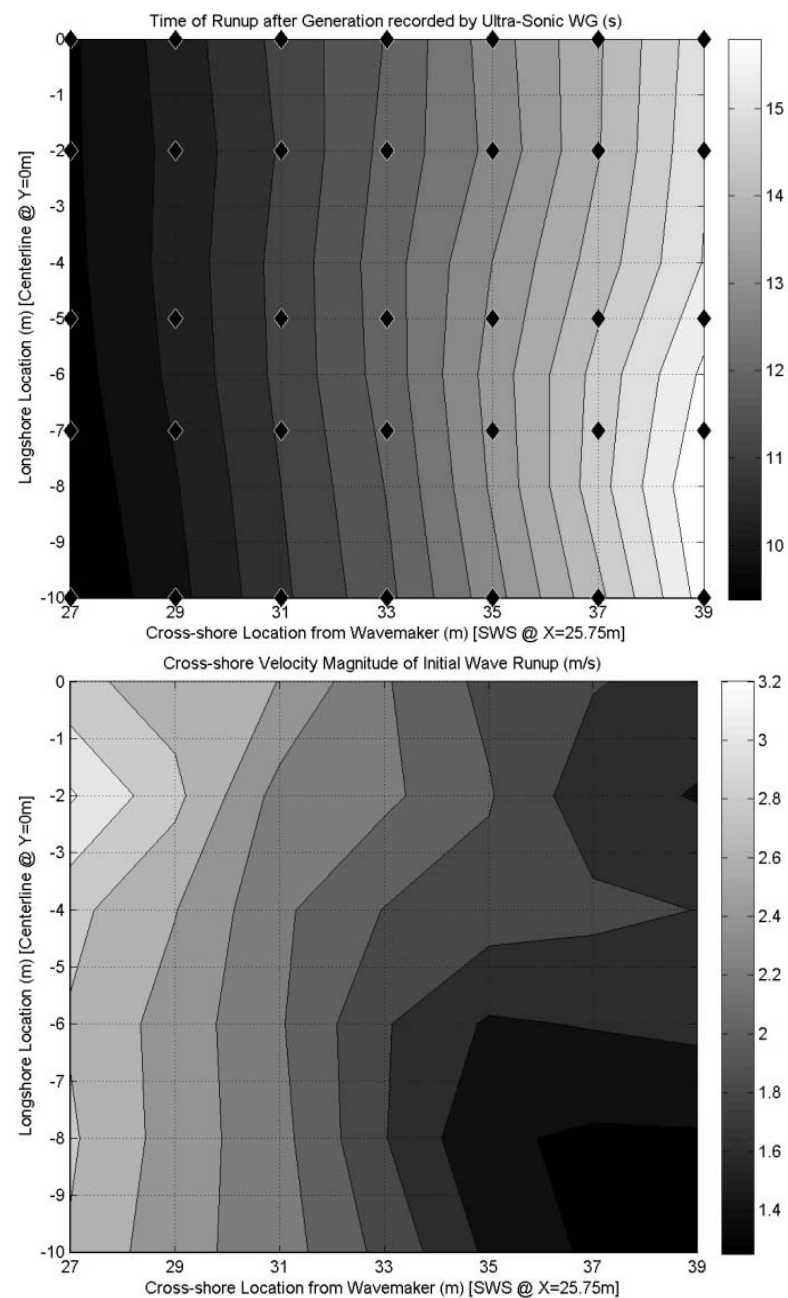

Figure 7. The arrival time (top) and bore front speed (bottom) as recorded by the usWG, of the solitary wave borefront on the planar beach shoreward of the SWS. $(\diamond)$ represent usWG locations.

The cross-shore velocity was found by differencing the arrival times of the runup with respect to the known locations of the usWG. The right plot in Figure 7 revealed that the greatest velocity occurred at $X=27 \mathrm{~m}$ near the basin centerline, while the lowest velocity occurred at $X=39 \mathrm{~m}$ near the basin side wall. The greater cross-shore velocity along the centerline was due to a jetting mechanism that was created as the wave refracted over the shelf. The refraction led to centerline-directed flow, causing a flow convergence near the centerline. The convergence resulted in a shoreward jetting mechanism. This jetting caused the greatest velocity to initially be concentrated near the centerline and spread laterally over time at each sequential cross-shore location. Lateral variations in the borefront speed are $10 \%-30 \%$. Thus, the shape and velocity of the runup and its variation as it traveled up the beach were influenced by the bathymetry offshore of the SWS.

\section{CONCLUSIONS}

The laboratory study, presented above, investigated the interactions between a breaking solitary wave and a 3D shallow water shelf. Due to the shelf, the solitary wave broke as a strongly plunging breaker. The interaction of this solitary wave and its offshore return flow with the bathymetry led to the creation of four distinct wave events, termed borefronts, which propagated across the shelf. Free surface measurements allowed the evolution of the solitary wave to be recorded both offshore and onshore of the SWS. As the wave encountered the shelf, almost no shoaling was observed at the apex due to steep slopes, while noticeable shoaling was revealed along milder slopes near the basin side walls. Once the wave traveled over the shelf edge, the wave height rapidly decayed due to breaking.

When the solitary wave reached the SWS, flow over the planar beach was not uniform in the longshore direction with variations driven by the shelf bathymetry. Closest to the SWS, the wave arrived first near the basin side wall, but further up the initially dry beach, the wave arrived first near 
the centerline. Analysis of this alongshore variation shows that the cross-shore velocity was greatest near the centerline due to a focusing of wave energy, an amplification due to refraction-based flow convergence. Along with the borefront from the incident solitary wave, a total of three other bores were tracked using both the free surface and the fluid velocity data. The largest recorded turbulent events were directly linked to the passing borefronts, suggesting that horizontal shear was the major factor in causing turbulence on the shelf.

The information presented here provides both insight into long wave evolution over shallow bathymetry and a unique 3D dataset to validate and calibrate numerical models. While extrapolations to geophysical-scale events, such as tsunamis, need be done with great caution, a few relevant conclusions from this experiment can be made. While it is generally accepted that long wave runup is a primary function of the upper beach slope (e.g. Synolakis, 1987), shallow offshore bathymetry can also play a major, and possibly counterintuitive, role in the inundating wave properties. When considering processes dominated by turbulent dynamics, such as mixing and transport, this experiment indicates that the turbulence created through borefronts and spatial velocity gradients dwarfs that generated through bottom stress.

\section{ACKNOWLEDGMENTS}

This work was funded through NSF grant CMMI-0619083.

\section{REFERENCES}

Cea, L., Puertas, J., Pena, L., 2007. Velocity measurements on highly turbulent free surface flow using ADV. Experiments in Fluids 42, 333-348.

Grilli, S.T., Subramanya, R., Svendsen, I.A., Veeramony, J., 1994. Shoaling of solitary waves on plane beaches. Journal of Waterway, Port, Coastal, and Ocean Engineering 120 (6), 609-628.

Hsiao, S.C., Hsu, T.W., Lin, T.C., Chang, Y.H., 2008. On the evolution and run-up of breaking solitary waves on a mild sloping beach. Coastal Engineering 55, 975-988.

Lin, C., Hwung, H.H., 1992. External and internal flow fields of plunging breakers. Experiments in Fluids 12, 229-237.

Mathieu, J., Scott, J., 2000. An Introduction to Turbulent Flow. Cambridge University Press, Cambridge, United Kingdom.

Synolakis, C.E. 1987. The runup of solitary waves. J. Fluid Mech. 185 (1987), pp. 523-545.

Tennekes, H., Lumley, J.L., 1972. A First Course in Turbulence. MIT Press, Cambridge, Massachusetts.

Ting, F.C.K., Kirby, J.T., 1994. Observation of undertow and turbulence in a laboratory surf zone. Coastal Engineering 24, 51-80.

Ting, F.C.K., Kirby, J.T., 1995. Dynamics of surf-zone turbulence in a strong plunging breaker. Coastal Engineering 24, 177-204.

Ting, F.C.K., 2006. Large-scale turbulence under a solitary wave. Coastal Engineering 53, 441-462.

Ting, F.C.K., 2008. Large-scale turbulence under a solitary wave: Part 2 forms and evolution of coherent structures. Coastal Engineering 55, 522-536.

Socolofsky, S.A., Jirka, G.H., 2004. Large-scale flow structures and stability in shallow flows. Journal of Environmental Engineering Science 3,451-462. 